\title{
REMOTELY SENSED PHENOLOGY FOR MAPPING BIOMES AND VEGETATION FUNCTIONAL TYPES.
}

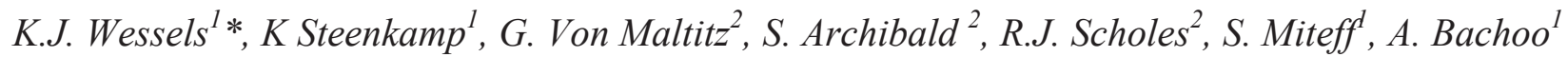 \\ ${ }^{* 1}$ Remote Sensing Research Unit, Meraka Institute, CSIR, Pretoria, South Africa, kwessels@csir.co.za \\ ${ }^{2}$ Ecosystems, Processes and Dynamics, Natural Resources and Environment, CSIR, Pretoria, \\ South Africa
}

\begin{abstract}
This study used remotely-sensed phenology data derived from Advanced Very High Resolution Radiometer (AVHRR), in a fully supervised decision-tree classification based on the new biome map of South Africa. The objectives were: (i) to investigate the long-term spatial patterns and inter-annual variability in satellite-derived vegetation phenology in relation to the recently revised biome map and (ii) to identify the phenological attributes that distinguishes between the different biomes. The long term phenometrics gave ecologically-meaningful results which reflect our current understanding of the spatial patterns of production and seasonality of vegetation growth in southern Africa. Regression tree analysis based on remotely-sensed phenometrics performed as good as, or better than, previous climate-based predictors of biome distribution.
\end{abstract}

Index Terms - AVHRR, phenology, biomes, vegetation mapping

\section{INTRODUCTION}

Vegetation biomes are traditionally mapped in one of two ways: (i) top-down - based on vegetation structural types and their association with regional climate [1], or (ii) bottom-up - by grouping vegetation types together based on composition and structure measured at the plot level [2]. There is a huge discrepancy between the scales and the measurement of regiona climate data and plot-level floristic data. Satellite-derived vegetation phenology data have tremendous potential for bridging the afore-mentioned gap in measurements, since they capture the spatial patterns of vegetation dynamics through repetitive observations at regional scales [3, 4]. Remotely sensed phenology are the ideal data on which to base regional vegetation classifications since they represent consistent measurements of vegetation processes and function and can be applied across vast areas with limited floristic data $[5,6]$. This study used remotely-sensed phenology data in a fully supervised decision-tree classification based on the new biome map of
South Africa [2]. This allowed a quantitative assessment of which phenological attributes are most characteristics of the newly defined biomes of South Africa.

The objectives of this study were therefore:

1. To investigate the long-term spatial patterns and inter-annual variability in satellite-derived vegetation phenology in relation to the recently revised biome map of South Africa

2. To identify the phenological attributes that distinguishes between the different biomes.

\section{METHODS}

\subsection{AVHRR data}

Advanced Very High Resolution Radiometer (AVHRR) data consisting of 10-day maximum value composite NDVI values (decads) at 1-km2 was used for the period 1985 2000. The processing and calibration of this Local Area Coverage (LAC) dataset is described in full elsewhere [7].

\subsection{Data filtering and phenometrics extraction}

A number of numerical methods have been developed to extract phenology metrics from long-term satellite vegetation index data $[3,4]$. These typically fit models to filter or smooth the noise in the time-series data (varying atmospheric conditions and sun-sensor-surface viewing geometries) [8] and then extract various metrics (referred to as phenometrics) from these models, e.g. start of growing season, peak of growing season, end of growing season, length of growing season, rate of greenup and integrated estimations of net primary production (NPP) (for review see [9]).

A widely used time-series analysis program, TIMESAT, was employed to calculate phenometrics from the AVHRR data [4]. An adaptive Savitsky-Golay filter, that uses a local polynomial fit together with small moving windows in two fitting steps to reduce noise and fit curves to the data. The threshold method used by TIMESAT provides a robust and computationally simple method for identifying SGS and 


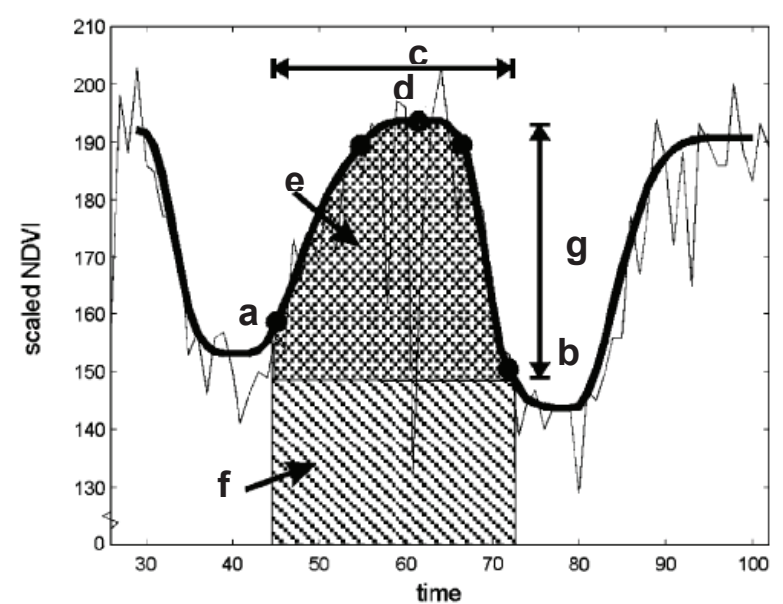

Figure 1. Phenometrics extracted from the seasonal NDVI curve, as defined in TIMESAT (after [4]).

Table 1. Date-related and productivity (NPP) - related phenometrics.

\begin{tabular}{|l|l|}
\hline Date-related metrics & NPP-related metrics \\
\hline $\begin{array}{l}\text { a. Start of growing season } \\
\text { (SGS) }\end{array}$ & $\begin{array}{l}\text { d. Maximum NDVI value } \\
\text { (MAX) }\end{array}$ \\
\hline $\begin{array}{l}\text { b. End of growing season } \\
\text { (EGS) }\end{array}$ & e. Small Integral (SI) \\
\hline c. Length of growth season & f. Large Integral (LI) \\
\hline $\begin{array}{l}\text { d. Mid position of growth } \\
\text { season }\end{array}$ & g. Amplitude \\
\hline
\end{tabular}

EGS of growing season as $20 \%$ of the seasonal amplitude (Fig. 2). The other seasonal phenometrics were calculated accordingly (Fig. 2)(Table 1).

Transformed areas such as cultivated land, plantations and built-up areas mapped in National Land Cover 2000 were excluded from further analyses which were only concerned with natural vegetation. A buffer of $1 \mathrm{~km}$ around the transformed areas was also excluded to avoid adjacency effects. 400 pixels per biome were randomly selected from the remaining untransformed areas. The same points were used for the savanna bioregion analysis.

\subsection{Phenology-based regression tree analyses}

A random forest regression tree was run using a range of phenometrics as the input variables and the biomes (Mucina \& Rutherford, 2006) respectively as dependent variables. No prior probabilities were used. The results of the phenology-based regression tree was compared to those of the a climate-based regression tree analyses (Mucina \& Rutherford, 2006). The resulting random forest model was used to run a prediction which mapped the biomes and savanna bioregions based on the phenometric data which was then assessed in terms of users and producers accuracy.

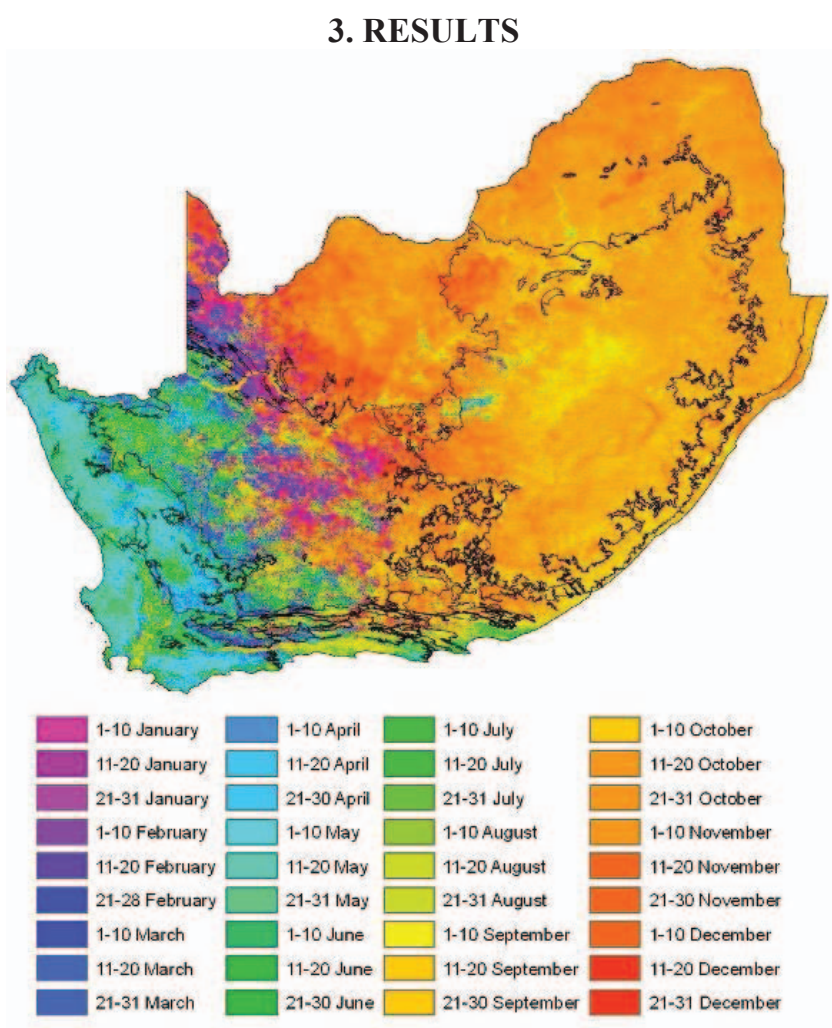

Figure 2. Mean start of the growing season (SGS).

\subsection{Phenometrics}

Phenometrics for each of the growing season were extracted and long-term means, standard deviations (SD) or coefficients of variation (CV) were calculated and mapped for all phenometrics across the periods 1985-1993 and 1995-2000 (data gap 1994). The SGS clearly reflect the east-west trend in start of growing season from summer to winter (Fig. 2)

The difference in seasonality is also clearly captured in Fig. 3. The majority of the pixels in the Savanna have a start of growing season in late October, midposition in February and end in June (Fig. 3). In contrast, the winter rainfall Succulent Karoo have a start of growing season in early June, midposition in August and end in December (Fig. 3). The Fynbos, though predominantly in a winter rainfall region is known to span from winter in the west to summer rainfall regions in the east (Figs 2, 3). The areas in the western Fynbos with later start dates (Oct) are mainly wheat fields where the pattern of planting and harvesting gives very uniform phenologies that are distinctly different from the surrounding fynbos vegetation.

\subsection{Regression tree analysis}

The regression tree initially split the biomes based on vegetation production and then by the seasonality of growth 
(Fig. 4). The three arid biomes (Desert, Succulent and Nama

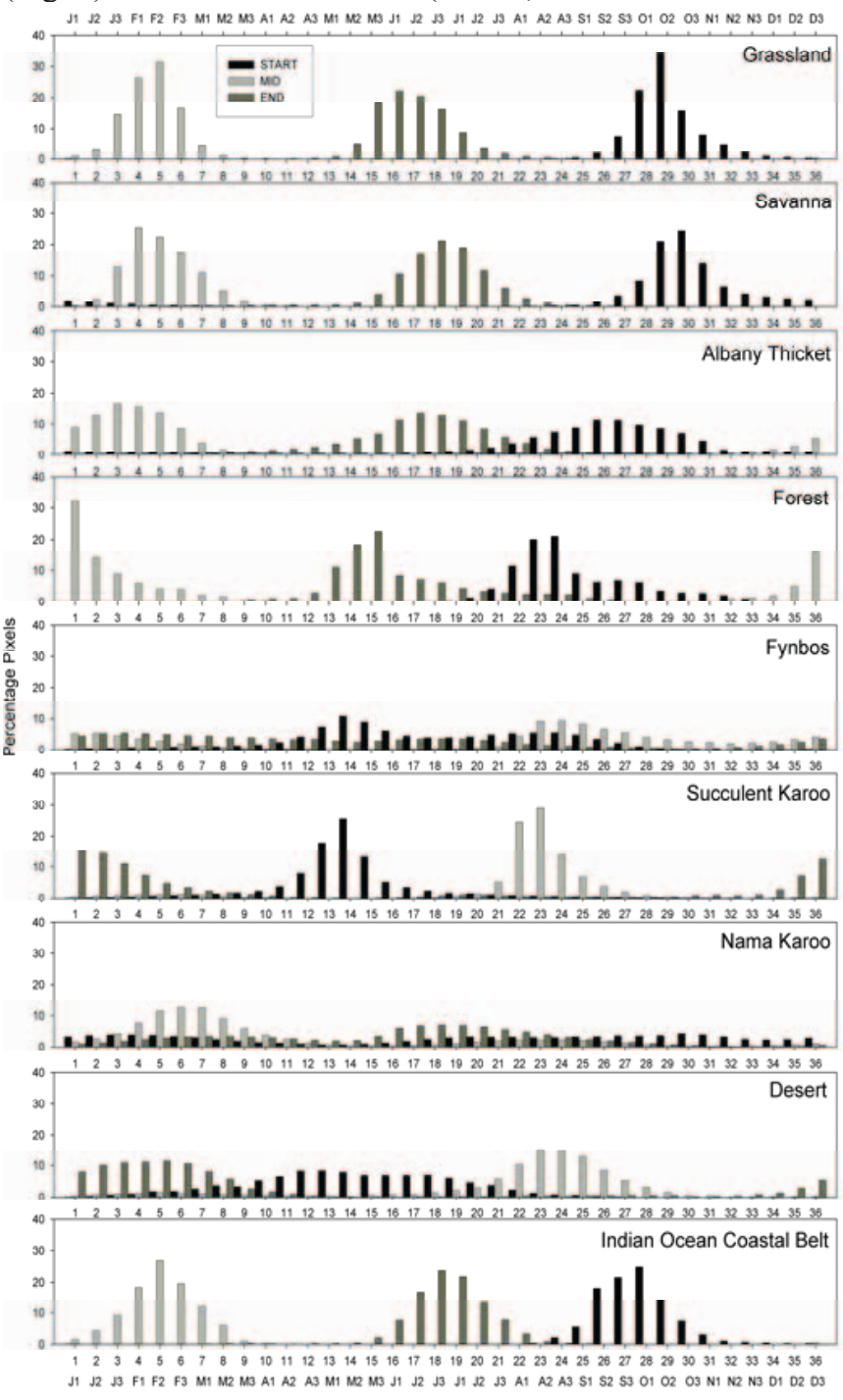

Figure 3. Frequency histograms of the mean START, midposition (MID) and END date of the growing season, per biome (South Africa). Numbered decads are named by the first letter of the month $(\mathrm{J}, \mathrm{F}, \ldots \mathrm{D})$ followed by the decad number (1-3).

Karoo) were isolated as having LARGE integrals less than 4.7 and the two high-biomass biomes (Forest and Coastal vegetation) were isolated as having LARGE integrals greater than 10.9. These broad NPP-defined vegetation units were then sub-categorised using the timing of the growth season.

The winter rainfall Succulent Karoo biome is separated from the summer rainfall Nama Karoo biome by the midpoint of their growing seasons (pixels with midpoints before July were identified as Nama Karoo). The winter rainfall Fynbos is separated from the summer rainfall Grassland and Savanna by having a mean START date before the 1st of October (decad 27.5).

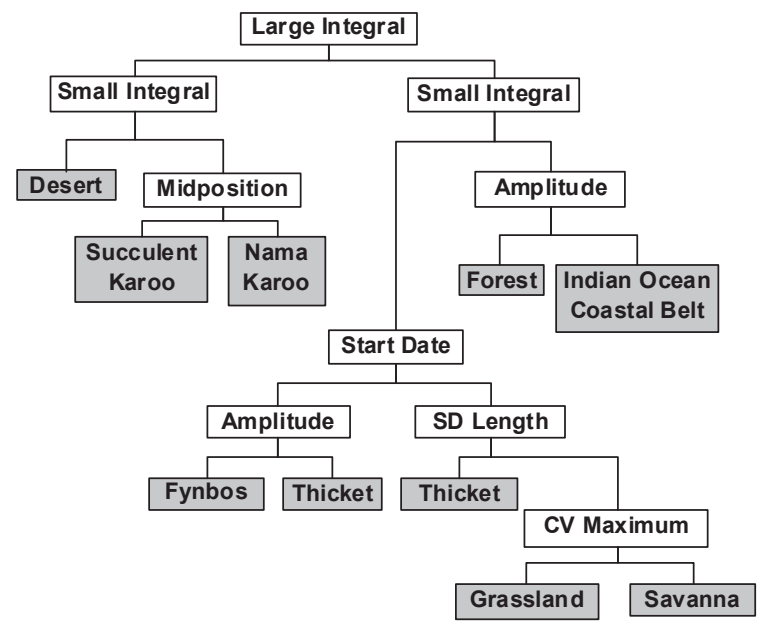

Figure 4. Phenology-based regression tree indicating split parameters for predicting biomes.

It is appropriate that Thicket was identified in both the winter and summer rainfall split, as this biome bridges the divide between the two climate regions. Thicket is identified as having a higher amplitude than Fynbos and a more variable growing season length than Grassland or Savanna. The split between Grassland and Savanna indicated that Grassland has a lower inter-annual coefficient of variation in its MAX value than Savannas (Fig. 4). This is due to the fact that the Savanna stretches into very arid areas in the north-western Kalahari resulting in the Savanna having a higher CV MAX.

The overall accuracy of the climate-based biome prediction (Mucina \& Rutherford, 2006) (Fig. 5) and the phenometric-based biome prediction (Fig. 4) were quite similar: $78 \%$ and $75 \%$ respectively (Table 3 ).

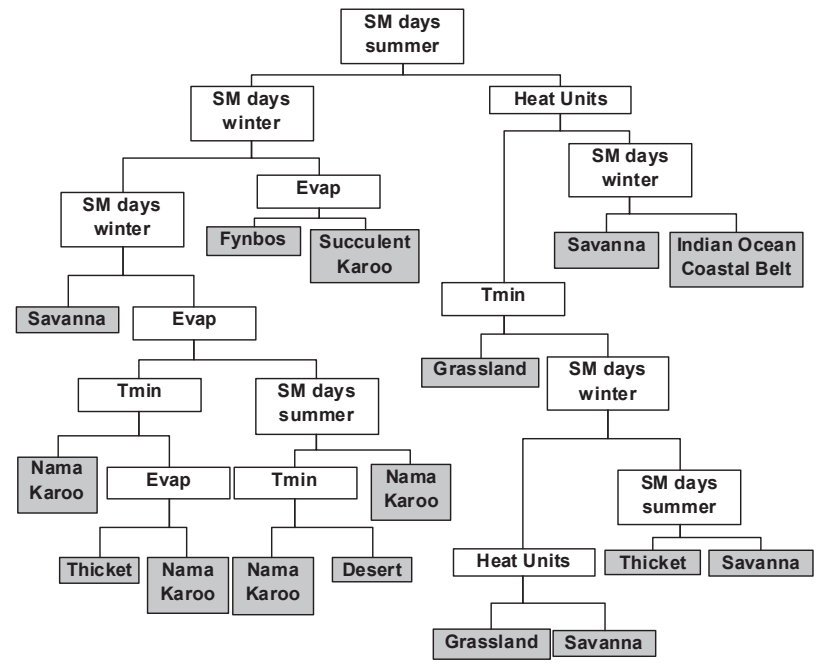

Figure 5. Climate-based regression tree indicating split parameters for predicting biomes. 
However, the broad-scale climatic-based tree is unable to resolve the Forest biome, as in South Africa Forests occur in the same regional climate bounds as both Savanna and Grassland, while other factors such as micro-climate, topography, fire history and land use determine where Forest patches occur in this region.

In the climate-based tree rainfall divided by evaporation is used as a surrogate for productivity (Rutherford et al., 2006) and was used to separate the more productive Thicket from the arid Nama Karoo; and the more productive Fynbos from the arid Succulent Karoo. Number of high soil moisture days in summer versus winter were used to subcategorise, but this measure conflates productivity and season of growth the splits were less clear than in the phenology-based tree, with several different combinations of climatic conditions resulting in the same biome prediction.

Table 2. Accuracy of the random forest regression tree model developed on 3400 sample points from nine biomes. Values represent proportion of the sample points which were correctly classified by the Phenology-based model.

\begin{tabular}{|l|l|l|l|}
\hline Biome & $\begin{array}{l}\text { NPP-related } \\
\text { phenometrics }\end{array}$ & $\begin{array}{l}\text { Date-specific } \\
\text { phenometrics }\end{array}$ & $\begin{array}{l}\text { All } \\
\text { phenometrics }\end{array}$ \\
\hline Desert & 0.83 & 0.72 & 0.89 \\
\hline $\begin{array}{l}\text { Succulent } \\
\text { Karoo }\end{array}$ & 0.50 & 0.58 & 0.69 \\
\hline Nama Karoo & 0.39 & 0.49 & 0.67 \\
\hline Fynbos & 0.43 & 0.43 & 0.66 \\
\hline $\begin{array}{l}\text { Albany } \\
\text { Thicket }\end{array}$ & 0.47 & 0.56 & 0.70 \\
\hline Grassland & 0.71 & 0.67 & 0.76 \\
\hline Savanna & 0.15 & 0.62 & 0.71 \\
\hline Forests & 0.80 & 0.68 & 0.79 \\
\hline $\begin{array}{l}\text { Indian Ocean } \\
\text { Coastal Belt }\end{array}$ & 0.65 & 0.77 & 0.90 \\
\hline Total & 0.54 & 0.61 & 0.75 \\
\hline
\end{tabular}

\section{CONCLUSIONS}

The long term phenometrics gave ecologically-meaningful results which reflect our current understanding of the spatial patterns of production and seasonality of vegetation growth in southern Africa. Regression tree analysis based on remotely-sensed phenometrics performed as good as, or better than, previous climate-based predictors of biome distribution. The results suggest that phenometrics capture sufficient functional diversity to classify and map vegetation based on function. They furthermore indicate a convergence of vegetation structure and function at the biome level.

\section{REFERENCES}

[1] M. C. Rutherford and R. Westfall, "Biomes of southern Africa - an objective categorization.," Memoirs of the Botanical Survey of South Africa., vol. 63, pp. 1-94, 1994.
[2] M. C. Rutherford, L. Muncina, and L. W. Powrie, "Biomes and bioregions of Southern Africa.," in The vegetation of South Africa, Lesotho and Swaziland., L. Muncina and M. C. Rutherford, Eds. Cape Town: Strelitzia, 2006, pp. 32-50.

[3] B. C. Reed, M. A. White, and J. F. Brown, "Remote Sensing Phenology," in Phenology: An Integrative Science, M. D. Shwartz, Ed. Dordrecht: Kluwer Academic Publishing, 2003.

[4] P. Jönsson and L. Eklundh, "Seasonality Extraction by Function Fitting to Time-Series of Satellite Sensor Data.," IEEE Transactions on GeoScience and Remote Sensing, vol. 40, pp. 1824-1832, 2002.

[5] D. Alcaraz, J. Paruelo, and J. Cabello, "Identification of current ecosystem functional types in the Iberian Peninsula," Global Ecology and Biogeography, vol. 15, pp. 200-212, 2006.

[6] J. M. Paruelo, E. G. Jobbagy, and O. E. Sala, "Current distribution of ecosystem functional types in temperate South America," Ecosystems, vol. 4, pp. 683-698, 2001.

[7] K. J. Wessels, S. D. Prince, N. Zambatis, S. MacFadyen, P. E. Frost, and D. VanZyl, "Relationship between herbaceous biomass and 1-km² Advanced Very High Resolution Radiometer (AVHRR) NDVI in Kruger National Park, South Africa.," International Journal of Remote Sensing, vol. 27, pp. 951-973, 2006.

[8] J. N. Hird and G. J. McDermid, "Noise reduction of NDVI time series: An empirical comparison of selected techniques," Remote Sensing of Environment, vol. 113, pp. 248-258, 2009.

[9] M. A. White, K. M. De Beurs , K. D. Idan, D. W. Inouy, A. D . Richardson, O. P. Jensen, J. O'Keef, G. Zhang, R. R. Nemani, W.J. D . Van Leeuwen, J. F. Brown, A. De wit, M. Schaepman, X. Lin, M. Dettinger, A. S. Bailey, J. Kimball, M. D. Schwartz, D. D . Baldocchi, J.T. Lee, and W. K. Lauenroth, "Intercomparison, interpretation, and assessment of spring phenology in North America estimated from remote sensing for 1982-2006.," Global Change Biology, pp. doi: 10.1111/j.13652486.2009.01910.x, 2009. 